This item was submitted to Loughborough's Research Repository by the author.

Items in Figshare are protected by copyright, with all rights reserved, unless otherwise indicated.

Using stereolithography tools for injection moulding: research into tensile tool failure and unexpected benefits of the process

PLEASE CITE THE PUBLISHED VERSION

PUBLISHER

(C) Professional Engineering Publishing

LICENCE

CC BY-NC-ND 4.0

REPOSITORY RECORD

Hopkinson, Neil, and Phill M. Dickens. 2019. “Using Stereolithography Tools for Injection Moulding: Research into Tensile Tool Failure and Unexpected Benefits of the Process". figshare. https://hdl.handle.net/2134/3565. 
This item was submitted to Loughborough's Institutional Repository by the author and is made available under the following Creative Commons Licence conditions.

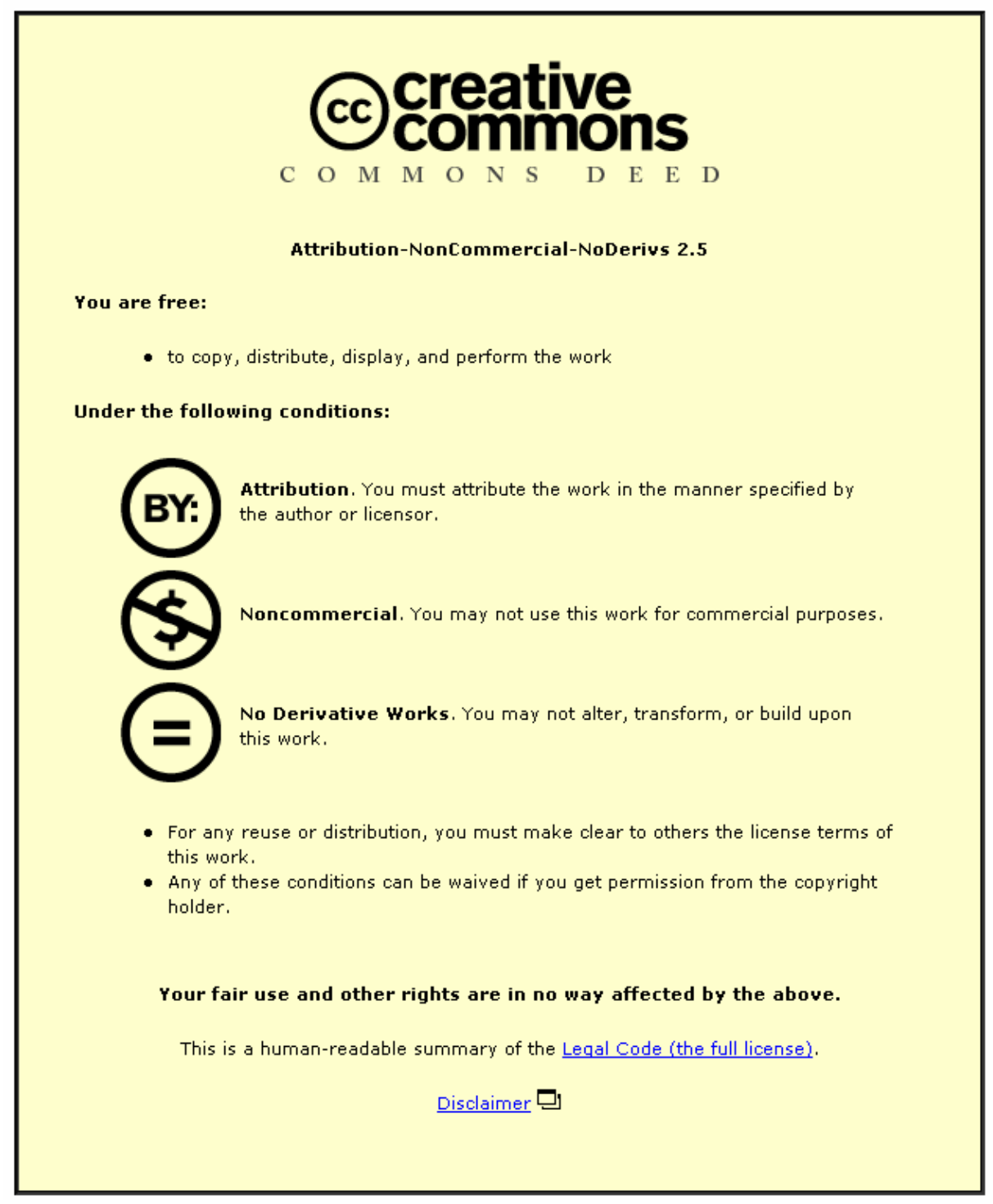

For the full text of this licence, please go to: http://creativecommons.org/licenses/by-nc-nd/2.5/ 


\title{
Using stereolithography tools for injection moulding: research into tensile tool failure and unexpected benefits of the process
}

\author{
N Hopkinson* and P M Dickens \\ Department of Mechanical and Manufacturing Engineering, De Montfort University, Leicester, UK
}

\begin{abstract}
The use of stereolithography (SL) parts as injection moulding tools offers many advantages over traditional tool making approaches. In particular, the time required to convert a computer aided design (CAD) file to the final tool is dramatically reduced as may be the costs in creating the tool. However, the process has been perceived to have a number of drawbacks which are, in the main, associated with the poor thermal and mechanical properties of the SL resins.

Research was performed which involved the production and use of an SL tool to injection mould a series of parts in polypropylene. Measurements were made of the forces required to eject parts from the tool in order to assess the possibility of tensile tool failure during part ejection. The measured forces were compared with predicted values which had been calculated using previously devised equations. In addition, temperatures were recorded throughout the injection moulding cycle to assess the tool's strength at different times. Surface roughness measurements were also taken to characterize the ejection process more closely and observe any changes to surface roughness caused by moulding parts. A finite element analysis was made of the heat transfer in the tool to help with prediction of ejection forces.

Measurements of ejection forces and heat transfer indicated that, contrary to existing recommendations, part ejection should be performed shortly after injection. Accurate predictions of ejection force were shown to be unattainable given the difficulty in finding accurate values for the variables used in the force prediction equations. Measurements of heat transfer coupled with surface roughness suggested that the low thermal properties of SL tools actually work in favour of the process rather than against it. This conceptual about-turn regarding the role of thermal properties in SL injection moulding tools indicates that further benefits may be derived from the new technology.
\end{abstract}

Keywords: rapid prototyping, stereolithography, injection moulding

\section{NOTATION}

$A$ area of contact between core and moulding in direction of ejection $\left(\mathrm{mm}^{2}\right)$

$D \quad$ diameter of core (mm)

$E \quad$ Young's modulus of moulding material at $T_{\mathrm{e}}(\mathrm{MPa})$

$F_{\mathrm{e}} \quad$ ejection force $(\mathrm{N})$

$L \quad$ length of core (mm)

$P \quad$ contact pressure between mould and moulding (MPa)

$t \quad$ thickness of moulding (mm)

The MS was received on 14 October 1999 and was accepted after revision for publication on 20 March 2000.

${ }^{*}$ Corresponding author: Department of Mechanical and Manufacturing Engineering, De Montfort University, The Gateway, Leicester LE1 $9 B H, U K$
$T_{\mathrm{e}} \quad$ ejection temperature of moulding material $\left({ }^{\circ} \mathrm{C}\right)$

$T_{\mathrm{m}}$ melting temperature of moulding material $\left({ }^{\circ} \mathrm{C}\right)$

$\alpha \quad$ coefficient of thermal expansion of moulding material $\left(\mathrm{K}^{-1}\right)$

$\mu \quad$ coefficient of friction between moulding material and core

$\gamma \quad$ Poisson's ratio for moulding material

\section{INTRODUCTION}

In recent years manufacturers have found an increased need to shorten product development cycles in order to achieve a quicker time to market for new products. Rapid prototyping (RP) technologies have proved to 
be a particularly useful tool in terms of speeding up the product development cycle [1]. RP technologies all work on the principle of stacking two-dimensional layers of materials on top of each other to produce a three-dimensional part. RP parts may be used during various stages of the product development cycle including:

(a) basic prototypes for visualization using processes such as fused deposition modelling, three-dimensional printing using starch powder and wax jetting,

(b) master patterns to create prototype tooling in processes such as vacuum casting and investment casting and

(c) tools for short-run injection moulding using processes such as stereolithography (SL), three-dimensional printing using metal powder and selective laser sintering.

SL is considered to be the original and one of the leading RP technologies. The SL process starts in the same way as all the other RP processes with a three-dimensional computer aided design (CAD) model of a part required in .stl (surface tessellation) format. The CAD model is sliced into a number of layers which may typically be between 0.025 and $0.15 \mathrm{~mm}$ thick. The solid part is created when a laser, which is driven by the CAD data, selectively passes over the surface of a vat of uncured photosensitive epoxy resin. The laser initiates a reaction in the resin causing it to solidify and so a solid twodimensional epoxy profile is created. The solid twodimensional profile is attached to a platform which is lowered by the required layer thickness in the vat. A subsequent layer is attached to the top of the previous layer when the laser selectively passes over the surface of the resin once more. The process is repeated until a solid epoxy part has been made. In most cases the solid epoxy part is subjected to some finishing and further curing in an ultraviolet oven.

The SL process may be used to create an injection moulding tool into which plastic material will be injected. The main reason for using SL tools is to injection mould prototype parts in the final production material using the final production process in a fraction of the time and at a reduced cost when compared with using conventionally machined metal tooling [2]. Using SL tools can result in some problems especially when caution, which may not be required with metal tools, is not taken. The main problem encountered when using SL tools is that the tool breaks, and this can be due to many reasons. SL tools have material properties such as tensile strength, Young's modulus and shear strength which are considerably lower than those for metals such as aluminium or steel. The problem is exacerbated by increases in tool temperature, which result in further deterioration in mechanical properties [3] when hot plastic is injected. Another major drawback with the process is the low thermal conductivity of the tools [2] which results in increased cycle times and the tendency of operators to inject material while the tool is still hot and therefore weak. The low thermal conductivity can work in favour of the process by allowing the use of low injection speeds and pressures which will reduce the possibility of tool failure. The combination of the requirement for non-standard moulding process parameters coupled with the frequently catastrophic tool failure has often lead to moulders abandoning the use of SL tools after a few unsuccessful attempts.

\section{BACKGROUND}

Currently a great deal of research into SL injection mould tooling is being performed in order to understand best practice and to reduce the possibility of catastrophic failure so that the process and its benefits are more widely used [4-6]. The work presented in this paper has been designed to address a phenomenon of SL tooling which results in tensile failure of core features during part ejection. The problem occurs when hot plastic is moulded around a tool feature and as the plastic cools it grips onto the core feature (see Fig. 1). When the mould is opened and the part ejected, the friction between the moulding and the core feature may be greater than the tensile strength of the core feature, resulting in tensile failure of the tool (see Fig. 2).

The research presented below was intended firstly to help to predict whether a core feature of known dimensions on a tool would fail in tension during part ejection.

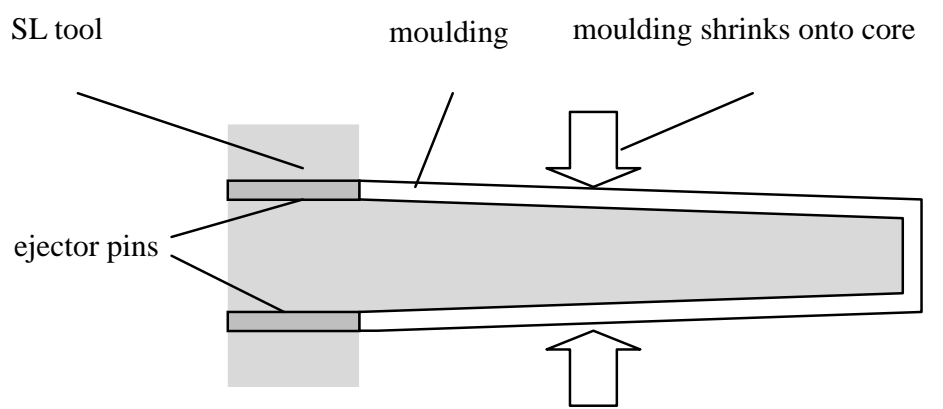

Fig. 1 Cross-sectional view showing how moulding cools on to the core 
ejector pins push forward core breaks moulding sticks to core

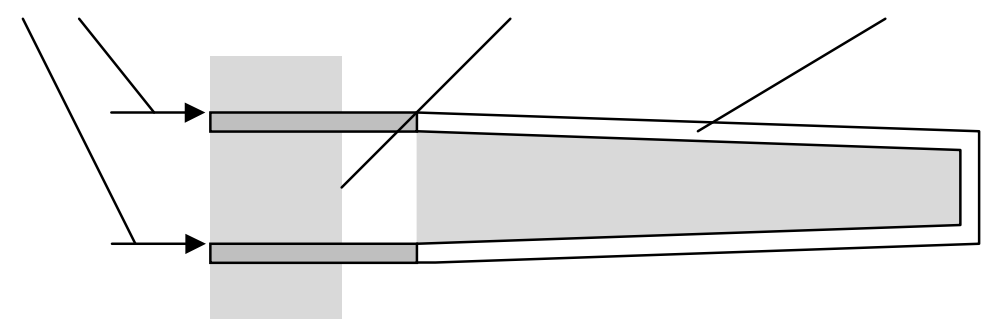

Fig. 2 Ejector pins push forward with a force greater than the tensile strength of the tool

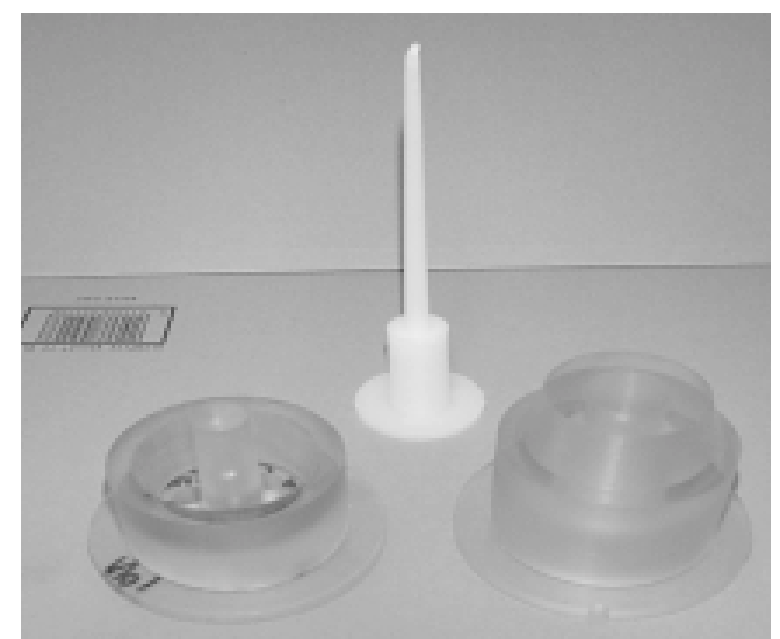

Fig. 3 Picture of complete moulding along with SL core and cavity

Such predictions would allow a manufacturer to decide whether or not to use an SL tool for a certain design. In addition, by performing experiments it was hoped that new process parameters which reduce the possibility of tool failure would be found. In the experiments performed it was decided to measure the ejection forces required along with heat transfer (and hence tool strength) throughout the injection moulding cycle.

Additional measurements of surface roughness of the tool and the mouldings were taken in order to characterize the process more closely. Figure 3 shows a picture of a completed moulding along with the core and cavity halves of the mould.

\section{METHODOLOGY}

The work presented has been based on an investigation of theoretical predictions of ejection forces along with measurements taken in various experiments. Details of how this work was performed is given below.

\subsection{Finite element analysis modelling}

The finite element analysis (FEA) work was performed in order to predict the rate at which the polypropylene would cool in the mould. This in turn would help to predict how much the moulding had contracted onto the core at the time of ejection. The equations shown in Section 3.2 make use of the temperature of the melt material at the point of ejection to predict the magnitude of the required ejection force.

The FEA model was loaded with material data (specific heat capacity, thermal conductivity and density) for the materials in the mould. The model was run using a transient thermal analysis using the Algor FEA package for a period of $120 \mathrm{~s}$ using $1 \mathrm{~s}$ intervals between successive calculations.

\subsection{Prediction of ejection force using equations}

A number of equations to predict ejection forces using steel moulds have been developed, the simplest of these being [7]

$$
F_{\mathrm{e}}=\mu P A
$$

A more empirical equation has been developed by Glanvill and Denton [8]:

$$
F_{\mathrm{e}}=\frac{\alpha\left(T_{\mathrm{m}}-T_{\mathrm{e}}\right) D E A \mu}{D[D /(2 t)-D \gamma /(4 t)]}
$$

This equation may be simplified for cylindrical cores as the diameter of the core $(D)$ cancels out on the top and bottom halves of the equation. This results in the simplified equation

$$
F_{\mathrm{e}}=\frac{\alpha\left(T_{\mathrm{m}}-T_{\mathrm{e}}\right) E \pi L \mu}{1 /(2 t)-\gamma /(4 t)}
$$

Glanvill and Denton's equation was used by inserting values based on previous research and the FEA work which had been used to model heat transfer in the tool.

\subsection{Injection moulding cycle}

Figure 4 shows a schematic of the complete experimental set-up including the injection moulding machine and data acquisition equipment. The SL inserts, which were made using SL7170 resin, shown in Fig. 3 were housed 


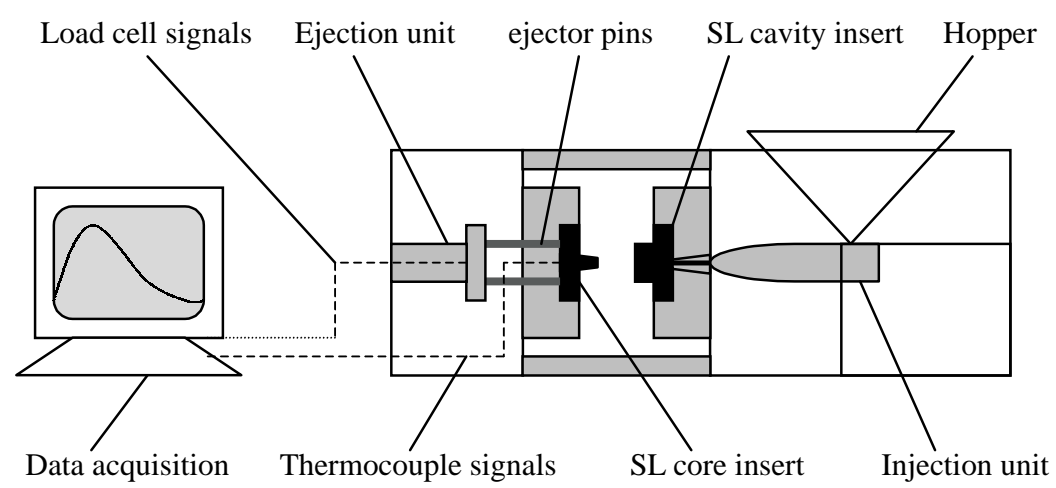

Fig. 4 Schematic diagram of the experimental set-up with the mould open

in a die set which was fixed to a 60 ton Battenfeld injection moulding machine. SL5170 resin was used as it had been successfully used in previous injection moulding research [4]. Cibatool 5530HT resin, which has a glass transition temperature $\left(T_{\mathrm{g}}\right)$ of over $100^{\circ} \mathrm{C}$, has been developed for injection moulding purposes; however, this material was not used as it had been shown to be susceptible to cracking during use in previous trials at De Montfort University and the Georgia Institute of Technology (USA). This susceptibility to cracking may be due to the low ductility (elongation at break, 2.9 per cent) [9] of the Cibatool 5530HT resin. It was possible to program various processing parameters such as injection speeds, holding pressure and ejection speed into the injection moulding machine. In order to maintain consistency between each shot, all parameters were unchanged with the exception of cooling time prior to ejection. For each shot the centre of the SL core was allowed to cool to $55^{\circ} \mathrm{C}$. This ensured that the core was not above its $T_{\mathrm{g}}$ during injection of the melt as this could have resulted in damage during injection. Table 1 shows the injection moulding parameters chosen for the SL tool along with those for a similar aluminium tool for the purposes of comparison. The moulding material was polypropylene with a melt flow index of 12 and a melting temperature of $160^{\circ} \mathrm{C}$.

\subsection{Measurement of ejection force from the SL core}

The die set included three ejector pins; each of these had a load cell housed behind it, as shown in Fig. 5. This

Table 1 Injection moulding parameters

\begin{tabular}{lll}
\hline Moulding process or parameter & SL tool & Aluminium tool \\
\hline Mould closing pressure $(\mathrm{MPa})$ & 5 & 40 \\
Melt temperature $\left({ }^{\circ} \mathrm{C}\right)$ & 185 & 190 \\
Injection speed $(\mathrm{m} / \mathrm{s})$ & 0.08 & 0.32 \\
Injection pressure $(\mathrm{MPa})$ & 10 & 40 \\
Follow-up pressure $(\mathrm{MPa})$ & 0 & 0 \\
Cooling time $(\mathrm{s})$ & $20-480$ & $5-45$ \\
Ejection speed $(\mathrm{m} / \mathrm{s})$ & 0.8 & 0.8 \\
Mould open time $(\mathrm{s})$ & 360 & 5 \\
\hline
\end{tabular}

allowed the ejection forces developed through each of the three ejection pins to be measured and added together to give the total ejection force. The total ejection force gave the tensile force which was applied to the core each time a part was ejected. The readings from the load cells were recorded using a data acquisition set-up at a frequency of $1000 \mathrm{~Hz}$ for each load cell. The ejection profile and peak ejection force were recorded for each part which was ejected.

\subsection{Measurement of temperatures in the SL core}

Temperature readings were taken from two thermocouples which were located in the core as shown in Fig. 6. Readings were recorded at $1 \mathrm{~s}$ intervals and these allowed the transfer of heat across the diameter of the core to be assessed. These measurements could then be used to predict tool strength at various stages during the cycle and ultimately to verify the output from the FEA model.

\subsection{Measurement of surface roughness}

A surface profilometer was used to measure the surface roughness and to show the roughness profile of the core's surface prior to use. Further measurements were taken from the core's surface after 50 shots had been moulded and ejected in order to show any changes

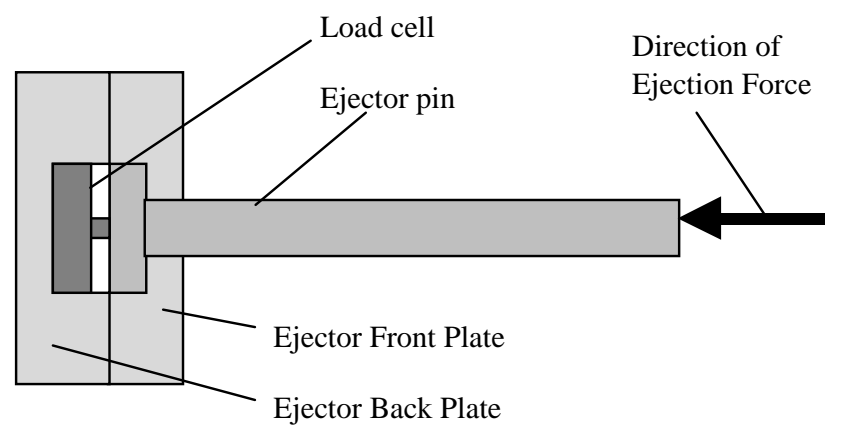

Fig. 5 Load cell located behind ejector pin to measure ejection forces 


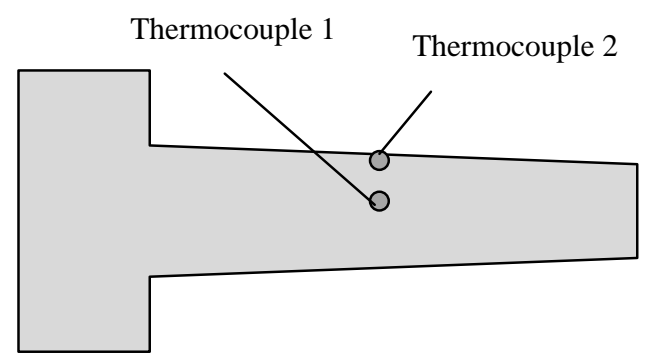

Fig. 6 Location of the thermocouples within the core

caused by moulding. Measurements were also taken from the inside surface of one of the mouldings for comparison with the surface of the core from which it was moulded.

\section{RESULTS}

\subsection{Predictions of $F_{\mathrm{e}}$}

The predictions of $F_{\mathrm{e}}$ were made using Glanvill and Denton's equation. Table 2 shows the values which were inserted into the equation. These values were based on previous research and published technical data with the exception of the ejection temperature $\left(T_{\mathrm{e}}\right)$ which was based on the output from the FEA model. Figure 7 shows the predicted polypropylene temperature change with time in the mould as given by the FEA model.

Predictions for the ejection force were made using the figures quoted in Table 2 along with the temperatures given by the FEA model at 20, 40, 60, 80, 100 and $120 \mathrm{~s}$ after starting the FEA model. It must be noted that the use of these figures to predict $F_{\mathrm{e}}$ was open to
Table 2 Values used to predict ejection forces

\begin{tabular}{ll}
\hline Variable in $F_{\mathrm{e}}$ equation & Value used \\
\hline$\alpha$ & $6.8 \times 10^{-5} \mathrm{~K}^{-1}$ \\
$T_{\mathrm{m}}$ & $160^{\circ} \mathrm{C}$ \\
$T_{\mathrm{e}}$ & FEA results (see Fig. 7) \\
$E$ & $245 \mathrm{MPa}\left(\right.$ at $\left.100^{\circ} \mathrm{C}\right)$ \\
$L$ & $38 \mathrm{~mm}$ \\
$\mu$ & 0.29 \\
$t$ & $2 \mathrm{~mm}$ \\
$\gamma$ & 0.35 \\
\hline
\end{tabular}

some error; e.g. the Young's modulus value of $245 \mathrm{MPa}$ is for polypropylene at $100{ }^{\circ} \mathrm{C}$ as no other values at elevated temperatures were available.

Figure 8 shows the predicted ejection forces given by substituting the chosen figures into Glanvill and Denton's equation. As expected, longer cooling times result in higher predicted ejection forces owing to increased contraction of the moulding onto the core.

\subsection{Measured ejection forces}

Figure 9 shows the measured ejection forces for different cooling times prior to ejection. The predicted values, which were shown in Fig. 8, are included for comparison.

The predicted ejection forces are around 30 per cent lower than the measured values; this may be due to the fact that some of the parameters used in the equation were estimates based on the best available data. This indicates that the equation and values may only be used as a rough estimator of ejection force.

The measured ejection forces show some inherent variation from 50 to $150 \mathrm{~N}$ for any given cooling time prior to ejection. One possible reason for the variation

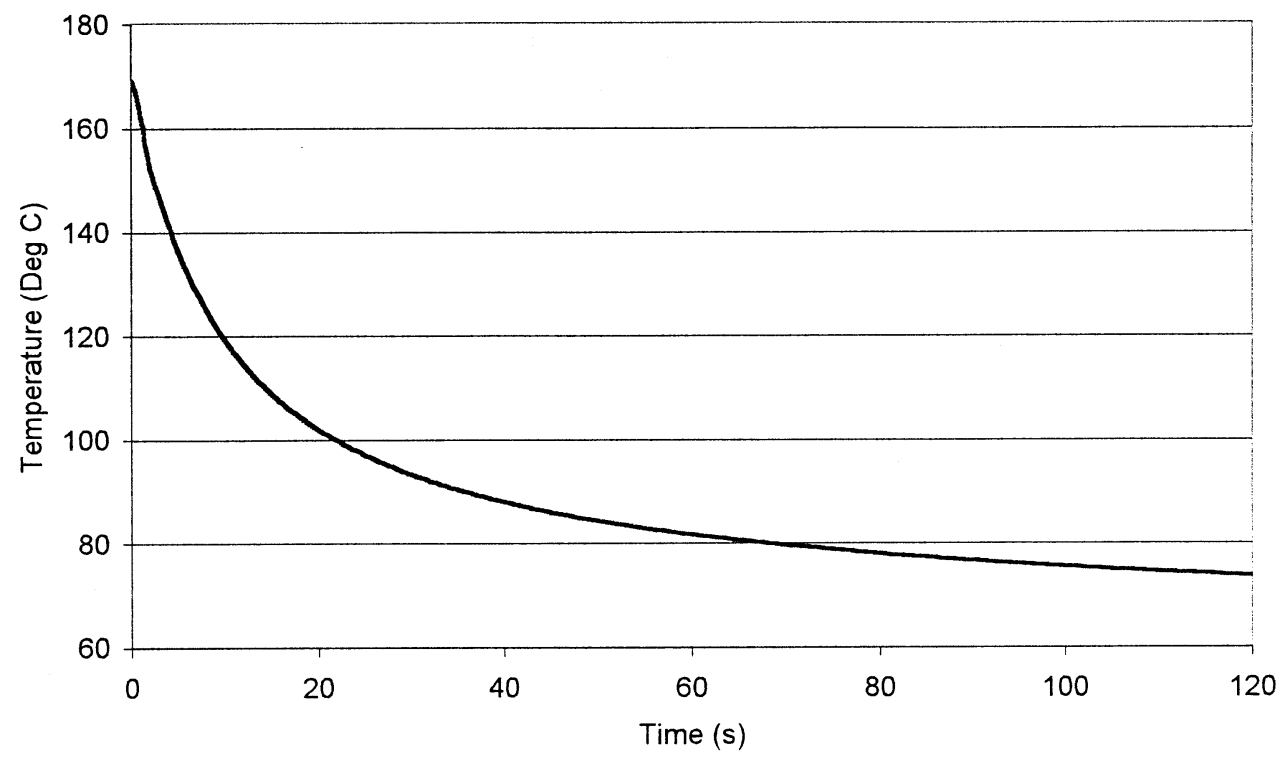

Fig. 7 Temperature output for polypropylene from the FEA model and used in the prediction of $F_{\mathrm{e}}$ 


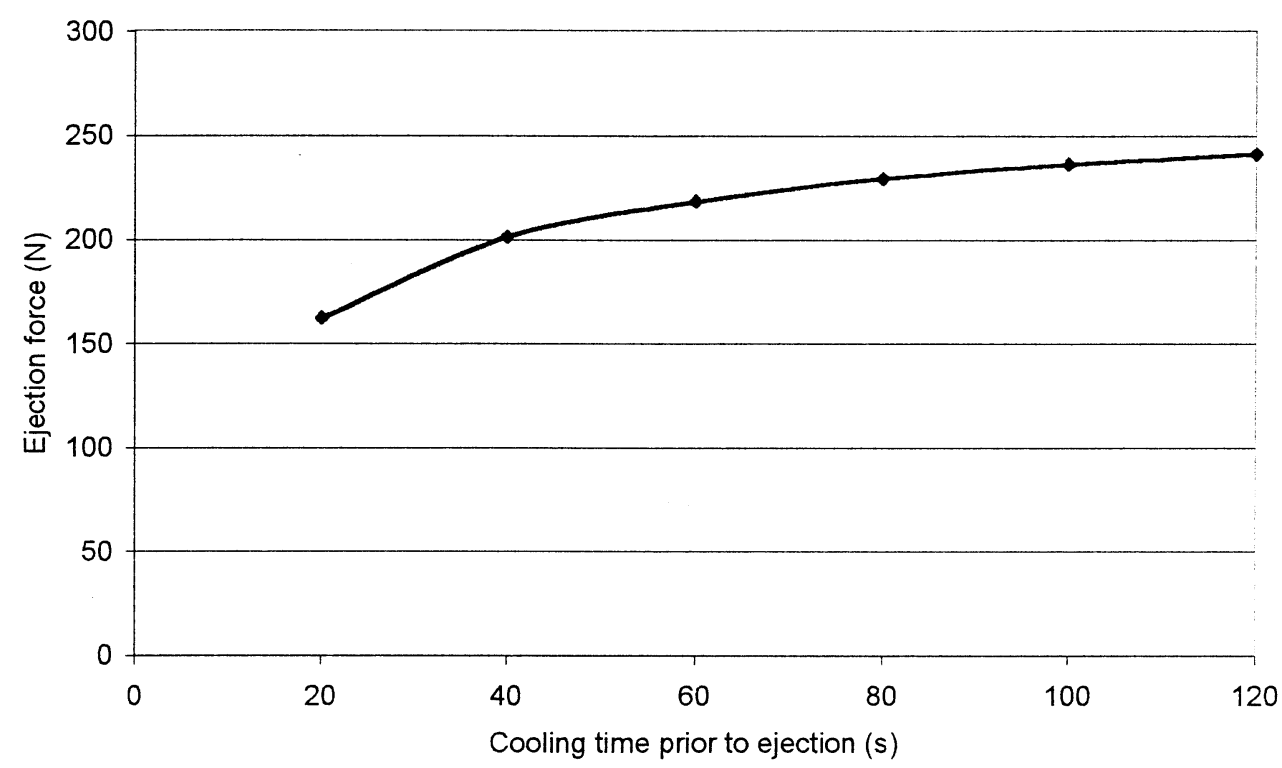

Fig. 8 Predicted ejection forces for different cooling times prior to ejection

was that the core may have smoothed over time leading to reduced ejection forces for later shots; however, there appeared to be no trends suggesting either increasing or decreasing ejection forces against the number of shots produced. Given that all parameters were kept consistent for each shot there is no clear explanation for this inherent variation in results.

\subsection{Measured temperature cycles}

Figure 10 shows the temperature cycles recorded by the thermocouples shown in Fig. 6. As expected, there was a sharp rise in temperature at the edge of the core immediately after the melt had been injected. The peak temperature of $82^{\circ} \mathrm{C}$ at the edge of the core was measured $25 \mathrm{~s}$ after injection had been completed.

Figure 10 shows that the temperature at the centre of the core actually dropped by $2{ }^{\circ} \mathrm{C}$ for the $20 \mathrm{~s}$ immediately after injection of the melt. This highlights the effect of the low thermal conductivity of the SL tool. The thermal lag caused by the low thermal conductivity is also indicated by the time of $110 \mathrm{~s}$ which was required before the centre of the core reached its peak temperature of $72^{\circ} \mathrm{C}$.

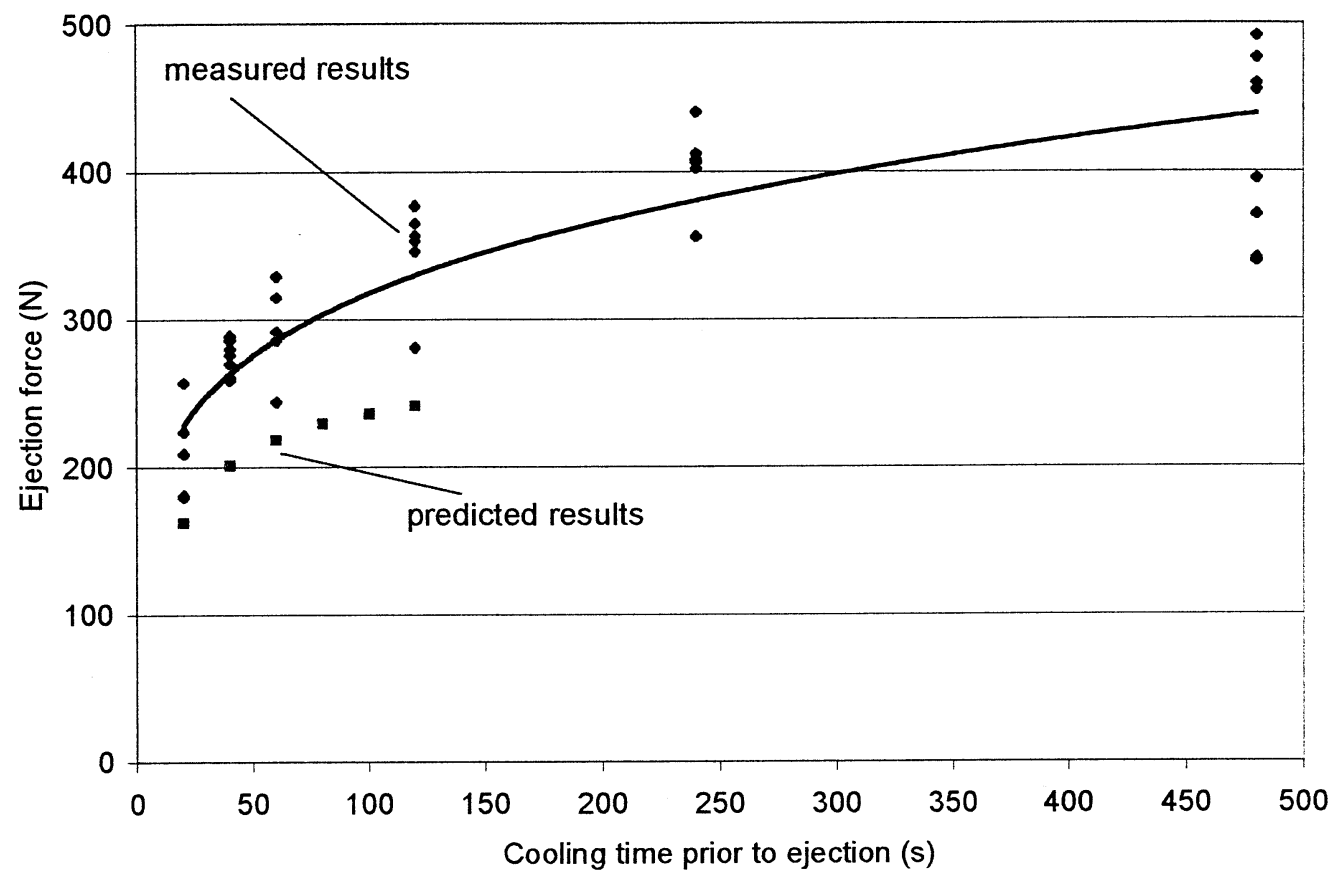

Fig. 9 Measured ejection forces along with predicted values 


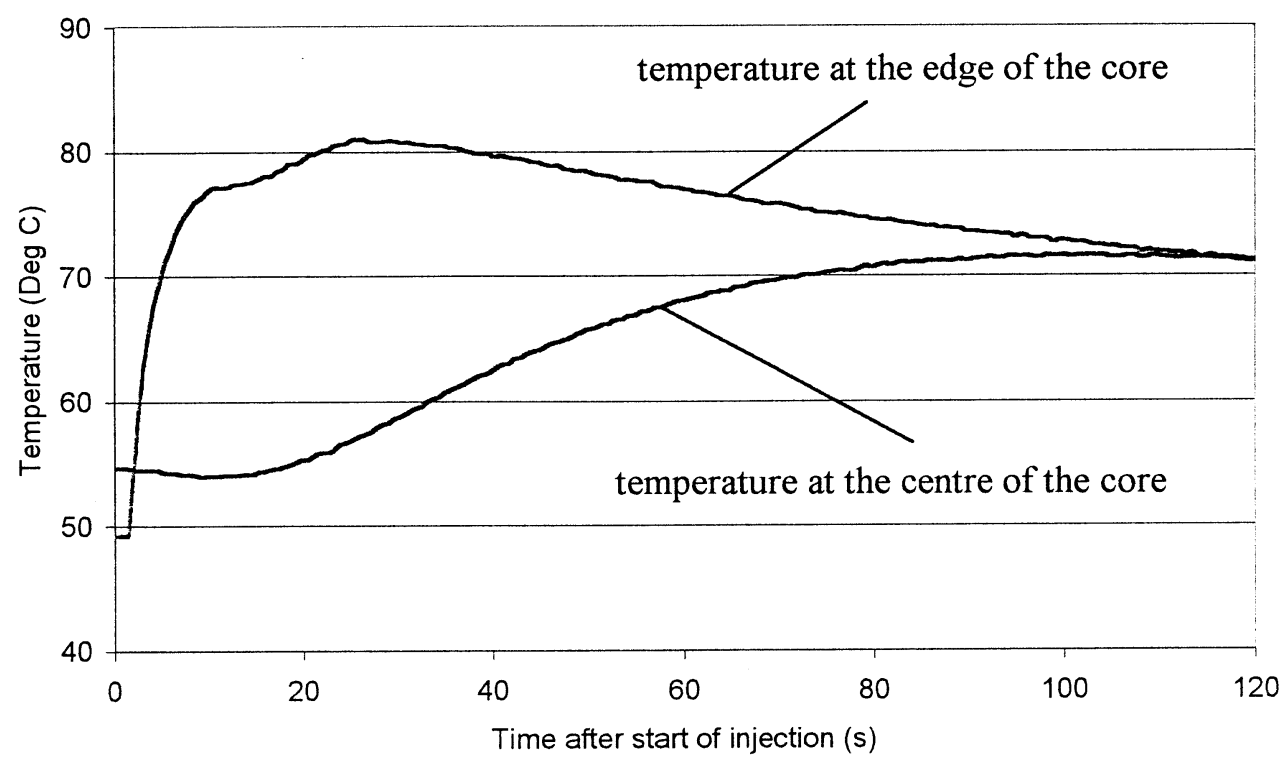

Fig. 10 Temperature cycles at the centre and edge of the core

\subsection{Surface roughness measurements}

Figure 11 shows a polar plot indicating the surface roughness measurements taken from the core's surface prior to moulding. The roughness appears to be reasonably uniform with most readings between 5 and $7 \mu \mathrm{m} R_{\mathrm{a}}$. One exception can be noted where a $9 \mu \mathrm{m} R_{\mathrm{a}}$ was recorded on the surface in a position where bubbles could be seen on the part. These results were consistent with previous investigations into the surface roughness of SL parts [10].

Figure 12 shows the surface roughness measurements recorded from the surface of the core after 50 shots had been moulded and ejected. The only noticeable change from the results taken prior to moulding was that the roughest point appeared to have been smoothed from 9 to $7 \mu \mathrm{m} R_{\mathrm{a}}$. Other discrepancies between results of about $1 \mu \mathrm{m} R_{\mathrm{a}}$ may be attributed to the repeatability of the profilometer used.

Figure 13 shows that the surface roughness measurements taken from the inside of the 50th moulding closely matched the readings taken from the outer surface of the core. This suggests that the molten polypropylene was able to penetrate the troughs in the surface of the core. In addition, there appears to be little or no evidence of either the core or the moulding surface being smoothed during ejection.

Figure 14 shows the surface roughness profiles recorded by the profilometer from the core's surface; the shape of the roughness features is consistent with previous findings. The similarity between the readings from before and after moulding supports the results

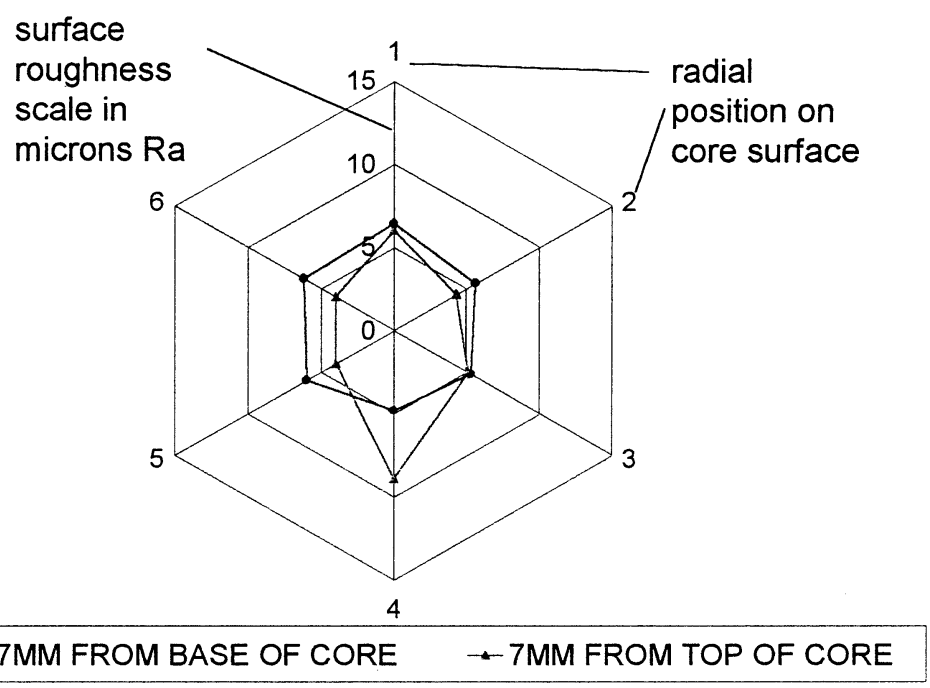

Fig. 11 Surface roughness of the core prior to moulding 


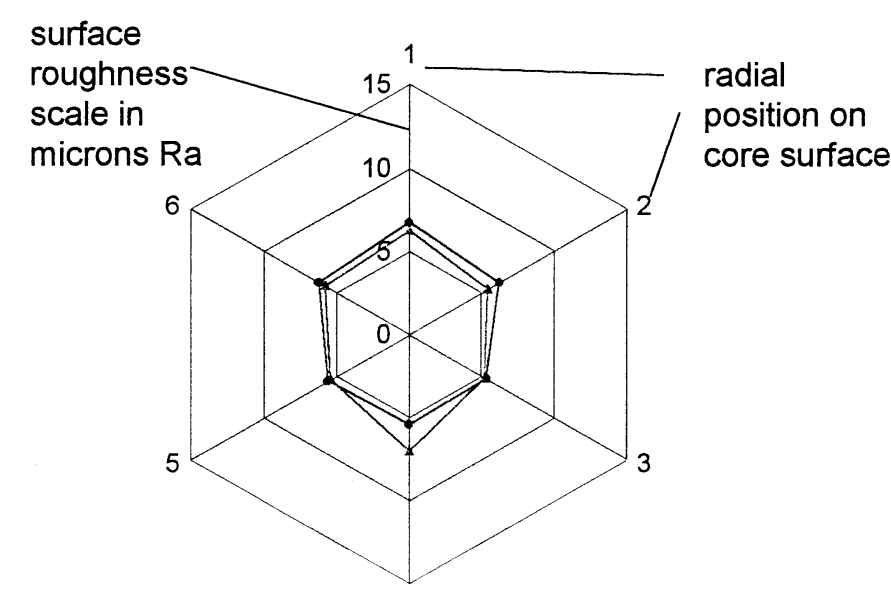

4

\section{$\bullet 7 M M$ FROM BASE OF CORE $\quad-7 \mathrm{MM}$ FROM TOP OF CORE}

Fig. 12 Surface roughness of the core after moulding 50 shots

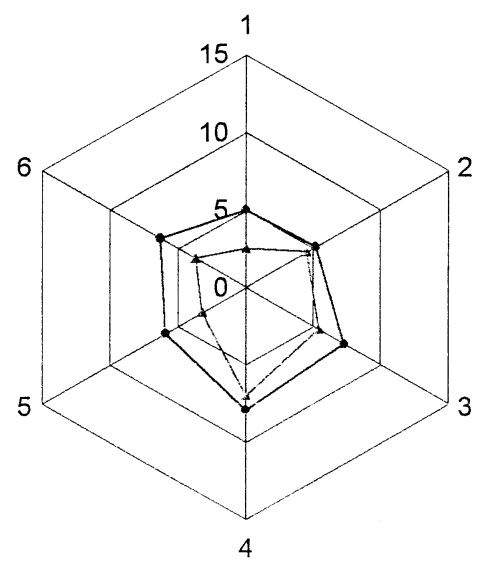

- $7 \mathrm{~mm}$ from base of moulding

$-7 \mathrm{~mm}$ from top of moulding

Fig. 13 Surface roughness of the inside of the 50th moulding

shown by the polar plots and suggests that moulding 50 polypropylene parts had no effect on the surface roughness of the tool.

Figure 15 shows that the surface roughness profile on the inside of the moulding mirrors that from the outside of the core. This is also consistent with the results from the polar plots suggesting that the molten polypropylene penetrates the troughs in the core's surface but no wear is observed during ejection.

\section{CONCLUSIONS}

\subsection{Ejection forces}

The magnitudes of the measured ejection forces were higher than those predicted using the equation developed by Glanvill and Denton. This suggests that only a rough estimate of ejection force may be made by using the equation. In addition, the variation of measured ejection

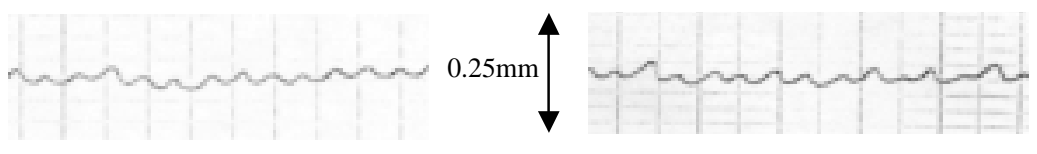

Before

After

Fig. 14 Tool surface roughness profiles before and after moulding 
$0.25 \mathrm{~mm}$

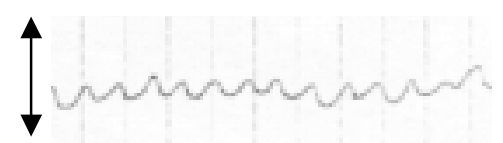

Fig. 15 Surface roughness profile of the inside of the 50th moulding

forces for a given cooling period prior to ejection suggests that attempts to predict ejection forces accurately with modified equations will be futile. As expected, a longer cooling time prior to ejection led to higher ejection forces; this suggests that, contrary to recommended procedure [11], as short a cooling time as possible should be used. Clearly the cooling time should be sufficient to allow the moulding to set and be resistant to damage on ejection. It may be useful to attempt to find the optimum cooling time prior to ejection by developing equations which predict heat transfer from the moulding into the tool.

\subsection{Temperature cycles and roughness measurements}

The low thermal conductivity of SL resin was highlighted by the slow thermal response at the centre of the core. This slow response suggests, especially with cores with larger cross-sections, that a short cooling time prior to ejection will reduce the thermal weakening of the tool and is therefore preferential; again this contradicts recommended procedure.

The temperatures measured at the surface of the core indicated that the surface over which the moulding is pushed during ejection is above its $T_{\mathrm{g}}$ for most of the cycle. SL resin which is above its $T_{\mathrm{g}}$ acts in a rubber-like manner and is able to bend freely and return to its original shape. This rubbery nature means that the core's surface is compliant on ejection and helps part ejection. Any deformation of either the core or the moulding surface is temporary and the surface features return to their original state once the part has been ejected.

\section{DISCUSSION}

At the start of this paper it was noted that the initial purpose of the research was to attempt to predict the circumstances under which tensile tool failure with SL cores would occur during part ejection. The outcome of the work has shown that precise forecasts of tools' tensile behaviour during ejection are impossible to make given the difficulty in accurately predicting ejection forces. However, a number of significant findings which should reduce the possibility of tensile tool failure during part ejection were found. The use of shorter cooling times prior to ejection appears to be beneficial as they lead to lower ejection forces, can limit thermal weakening of the tool and benefit from a compliant tool surface for ejection.

The limit on thermal weakening of the tool indicates that the low thermal conductivity of SL resin may be used to help the injection moulding process with these tools. Further benefits may be drawn from the low thermal conductivity including the ability to produce large mouldings on small machines as low injection and clamping pressures may be used without the melt shutting off. In addition, features such as thin ribs may be moulded where the high conductivity of metal tools would be prohibitive.

The compliant tool surface for ejection shows how the low $T_{\mathrm{g}}$ of the SL resin also helps rather than hinders the process. Another possibility for taking advantage of the low $T_{\mathrm{g}}$ is in the ejection of parts with small undercuts, removing the need for complicated sliding cores.

\section{REFERENCES}

1 Jacobs, P. F. Stereolithography and Other RP\&M Technologies, 1996 (American Society for Mechanical Engineers, New York).

2 Jacobs, P. F. Recent advances in rapid tooling from stereolithography. In Proceedings of the National Conference on Rapid Prototyping and Tooling Research, Buckinghamshire College, 18-19 November 1996.

3 Hague, R. J. M. The use of stereolithography models as thermally expendable patterns in the investment casting process. PhD thesis, University of Nottingham, January 1997.

4 Rahmati, S. and Dickens, P. M. SLA injection mould tooling. Prototyping Technol. Int., 1997, 172-176.

5 Hopkinson, N. and Dickens, P. M. Study of ejection forces in the AIM $^{\text {TM }}$ process. Mater. Des., June 1999, 20(2/3), 99105.

6 Cedorege, T., Le Baut, Y., Palmer, A. and Colton, J. Design rules for stereolithography injection moulding inserts. In Proceedings of the 8th European Conference on Rapid Prototyping in Manufacturing, Nottingham, 6-8 July 1999.

7 Menges, G. and Morhen, P. How to Make Injection Moulds, 1986 (Hanser, New York).

8 Glanvill, A. and Denton, E. Injection Mould Design Fundamentals, 1965 (Industrial Press, New York).

9 Rapid Prototyping Report-Annual Directory, 2000 (CAD/ CAM Publishing, San Diego, California).

10 Reeves, P. E., Dickens, P. M., Davey, N. and Cobb, R. C. Surface roughness of stereolithography models using an alternative build strategy. In Proceedings of the 6th European Conference on Rapid Prototyping and Manufacturing, Nottingham, 1-3 July 1997, pp. 85-94.

11 Decelles, P. and Barritt, M. Direct AIM ${ }^{T M}$ Prototype Tooling Procedural Guide, 1996 (3D Systems, Valencia, California). 